\title{
GOVERNANÇA CORPORATIVA: UMA ANÁLISE DA REPRESENTATIVIDADE DAS MULHERES NA DIRETORIA EXECUTIVA DAS EMPRESAS LISTADAS NA B3
}

Luís Fernando Gomes Albuquerque ${ }^{1}$ Anderson Sousa Santos ${ }^{2}$

\begin{abstract}
RESUMO
O debate sobre a diversidade de gênero nas empresas é algo cada vez mais discutido na sociedade, as próprias companhias enxergam como uma estratégia de negócio. Baseado nessas informações, buscou-se dados da distribuição percentual entre homens e mulheres na direção executiva das empresas listadas na B3, pertencentes aos segmentos ligados a Governança Corporativa, no ano de 2019. O objetivo deste trabalho é apontar a representatividade das mulheres no cargo de diretora executiva das empresas que seguem padrões de governança altamente diferenciados. Realizou-se uma pesquisa bibliográfica, onde buscou-se o conhecimento de autores renomados no assunto. Também foi realizado uma pesquisa do tipo descritiva, conduzida por meio de análise documental e uma abordagem quantitativa em amostra de 175 empresas. Levantou-se através do sítio eletrônico, disponibilizado pelas empresas, a quantidade de diretores e diretoras executivos. Considerou-se todo o corpo da diretoria executiva, incluindo cargos com a denominação de Presidente e Vice-Presidente. Realizou-se uma análise por segmento de governança e por setor de atuação. $\mathrm{O}$ resultado obtido entre os segmentos foi homogêneo. Porém, mesmo as empresas que possuem um padrão de governança diferenciado, precisam investir e ganhar maturidade sobre o tema diversidade de gênero. Os executivos precisam estar empenhados em igualizar essa lacuna existente entre homens e mulheres.
\end{abstract}

Palavra-chave: Governança Corporativa, Diversidade de Gênero, Maturidade

\section{CORPORATE GOVERNANCE: AN ANALYSIS OF WOMEN'S REPRESENTATIVITY IN THE EXECUTIVE BOARD OF COMPANIES LISTED IN B3}

\begin{abstract}
The debate about gender diversity in companies is increasingly discussed in society, companies themselves see as a business strategy. Based on this information, we sought data on the percentage distribution between men and women in the executive management of companies listed in B3, belonging to the Corporate Governance segments, in 2019. The objective of this paper is to point out the representation of women in the position of executive director of companies that follow highly differentiated governance standards. A bibliographic research was carried out, where the knowledge of renowned authors on the subject was sought. A descriptive research was also conducted, conducted through document analysis and a quantitative approach in a sample of 175 companies. Through the website, made available by the companies, the number of directors and executive officers was surveyed. The entire executive board was considered, including positions with the denomination of President and Vice President. An analysis was performed by governance segment and by sector. The result obtained between the segments was homogeneous. However, even companies that have a differentiated governance pattern need to invest and gain maturity on the topic of gender diversity. Executives need to be committed to bridging this gap between men and women.
\end{abstract}

Keywords: Corporate Governance, Gender Diversity, Maturity

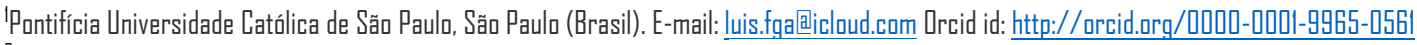

${ }^{2}$ Pantifícia Universidade Católica de São Paula, São Paulo (Brasil). E-mail: andersan国azienda.com.br 


\section{INTRODUÇÃO}

As mulheres na sociedade moderna mudaram sua perspectiva de vida e sua visão perante as empresas. Hoje elas exigem uma equiparação na condição de trabalho e nos salários pagos. Segundo Cox e Blake (1991), a diversidade nas organizações é uma busca por vantagens competitivas. Pois as organizações que estimulam as diferenças tendem a ser mais criativas, são inovadoras e se tornam bem vistas perante os consumidores. Para Dadfar e Gustavsson (1992) a diversidade quando bem administrada se torna um ativo para empresas, porém, quando não, pode trazer alguns efeitos negativos.

Uma pesquisa realizada pela Organização Internacional do Trabalho -OIT (2019), revela que mais de 75\% das companhias entrevistadas, 13 mil num total, distribuídas em 70 países, inclusive o Brasil, indica que a diversidade de gênero contribui para o melhor rendimento do negócio. Mas, um estudo realizado pela Professora Lígia Paula Pires Pinto Sica da Escola de Direito da Fundação Getúlio Vargas de São Paulo (2017), mostra que ainda há um longo caminho a ser seguido. "Notamos que, ao menos a nível nacional, a adoção dessas políticas de igualdade de gênero ainda é pouco avançada".

Segundo o Código das Melhores Práticas de Governança Corporativa do IBGC (2015), a Governança ampliou o papel das empresas e o impacto delas na sociedade. Honestidade, integridade e responsabilidade com a sociedade são fundamentais para a longevidade das companhias. Levando em consideração a adoção das práticas de governança e a responsabilidade com a sociedade, este estudo focou nas empresas listadas na B3, pertencentes aos segmentos de Governança Corporativa.

Nesse contexto, surge a pergunta que orienta este estudo: $\mathrm{O}$ fato de as empresas estarem listadas num segmento voltado à adoção de práticas de Governança Corporativa, faz com que elas adotem a mesma proporcionalidade na diretoria executiva entre homens e mulheres? O objetivo do estudo é medir a proporcionalidade das mulheres no cargo de diretoria executiva das empresas.

A motivação para este trabalho, decorre da crescente visibilidade que o tema: diversidade de gênero, vem ganhando nos últimos anos. Este estudo está estrutura em cinco seções, iniciando com essa introdução. Em seguida é 
apresentado o referencial teórico com embasamento de autores e pesquisadores sobre o tema. Após, a metodologia com os aspectos para o desenvolvimento da pesquisa. Em seguida, a análise dos resultados e pôr fim, considerações finais.

\section{REVISÃO BIBLIOGRÁFICA}

\subsection{GOVERNANÇA CORPORATIVA}

Para a governança corporativa, a companhia possui um propósito a ser perseguido. Os administradores são os responsáveis por nortear esse caminho. Segundo Mayer (2012), existem duas linhas de pensamento. Em uma linha, estão os defensores da maximização da riqueza dos acionistas, chamada primazia dos acionistas. Assim, para eles a companhia deve ter um único objetivo, aumentar a riqueza. Do outro lado, pensadores que acreditam que a companhia deve ter um propósito mais amplo. Nesse modelo, os administradores devem agir no melhor interesse de longo prazo da companhia, transcendendo o interesse do acionista e comtemplando os demais stakeholders.

Carvalho (2002), define governança corporativa como um mecanismo ou princípio que governa o processo decisório dentro de uma empresa. Já para Tirole (2001), é a defesa dos interesses dos acionistas, e uma boa estrutura de governança é aquela que seleciona os mais hábeis gerentes.

Já para, Machado Junior; Palmisano; Campanário (2015, p. 101)

A complexidade em gerir as organizações é um traço comum da história da humanidade. Uma importante colaboração para o estabelecimento de uma adequada gestão está associada à abordagem da Governança Corporativa, pela proposição de boas práticas, e seu respectivo conselho de administração

Uma pesquisa realizada por Ponte et al. (2012, p. 101 apud Machado Junior; Palmisano; Campanário, 2015, p. 101):

indica que as empresas brasileiras de capital aberto são motivadas a adotar as melhores práticas de Governança Corporativa no intuito de perpetuar a empresa, possibilitar transparência com o mercado de capitais, diminuir o custo de capital, edificar a imagem institucional e aumentar o valor da empresa. Os resultados obtidos na pesquisa dos autores refletem que o setor empresarial interpreta a Governança Corporativa como um fator benéfico e desejável para as empresas. 
Para o IBGC (2015, p. 20), organização de referência sobre o tema fundada em 1995, governança corporativa é

o sistema pelo qual as sociedades são dirigidas e monitoradas, envolvendo os relacionamentos entre Acionista/Cotista, Conselho de Administração, Diretoria, Auditoria Independente e Conselho Fiscal. As boas práticas de governança corporativa têm a finalidade de aumentar o valor da sociedade, facilitar seu acesso ao capital e contribuir para a sua perenidade.

Ainda segundo o instituto, a boa governança corporativa "assegura aos sócios equidade, transparência, prestação de contas (accountability) e responsabilidade pelos resultados". Ela é uma expansão do conceito de "conflito de agência", tratado pela teoria econômica tradicional. O conflito de agência é a diferença de interesses entre os proprietários e administradores da empresa, que traz à tona a necessidade de controles sobre estes interesses. Governança seria um conceito mais amplo do que meramente o controle. Abrange a "gestão estratégica da empresa e efetiva monitoração da direção executiva" (IBGC, 2015).

Segundo Silveira (2015, p. 3), governança corporativa diz respeito à maneira pela qual as sociedades são dirigidas. Incluindo regras que estabelecem o relacionamento dos seus personagens, como: diretoria, acionista e conselho de administração. Possui uma abordagem ampla, englobando áreas como: ética empresarial, gestão, liderança, finanças, direito, economia, contabilidade, psicologia e outras. Resumindo, visa a criar na empresa um ambiente onde as pessoas respeitem as regras impostas e possam tomar decisões no melhor interesse da organização. Para Valente (2018, p. 1), a governança corporativa de uma empresa estabelece uma estrutura na qual os indivíduos, que determinam o direcionamento da companhia, possam discutir e alinhar esse direcionamento, respeitando as normas e regras da empresa.

Para Mintzberg (2003, p. 24),

[...] Encarregada de assegurar que a organização cumpra sua missão de modo eficaz e também que atenda às necessidades dos que a controlam ou que detêm poder sobre ela (como seus proprietários, órgãos governamentais, sindicatos e empregados, grupos de pressão).

Há diversas teorias que explicam como as companhias devem ser governadas. Mas um bom sistema de governança depende da combinação de todas. A teoria da representação, ou agency theory, desenvolvida por Jensen e 
Meckling, é a mais abordada para os estudos da governança corporativa. Visa explicar como ocorre o desalinhamento entre executivos e acionistas. Os executivos, ou agents, são os representantes, os que tomam a decisão do negócio. Os acionistas, ou principals, são os representados, transferem seu poder de decisão para os executivos (SILVEIRA, 2015, p. 34). No mundo dos negócios, o conflito de agência dificilmente será evitado. Primeiramente pela inexistência de um contrato completo. Vivemos uma época onde a descontinuidade e a incerteza prevalecem. Transformações em comportamentos sociais, econômicas e tecnológicas. Diante das incertezas vivenciadas no mundo dos negócios, a gestão precisa se adaptar. Adaptar-se ao dinamismo e a velocidade da transformação (ROSSETTI; ANDRADE, 2016, p. 86). A inexistência do agente perfeito, é o segundo motivo para a existência do conflito de agência. Jensen e Meckling acreditam que a natureza humana conduz os indivíduos a maximizar suas preferências e os seus próprios objetivos. Dificilmente objetivos alheios movem pessoas a serem eficazes.

\subsection{DIVERSIDADE}

As organizações possuem uma pluralidade nas relações de trabalho interna, estas empresas buscam cada vez mais promover esta diversidade, estimulando os mais variados tipos de adversidade.

Na ótica de Cox e Blake (1991, apud Silveira, 2006), as organizações que estimulam e valorizam as diferenças de perspectivas como estratégia de negócios podem desenvolver a aprendizagem, criatividade, inovação, ter maior representatividade perante os consumidores e aumentar a atratividade e retenção de profissionais

Em sentido contrário Triandis (1995, apud Silveira, 2006) comenta que, "contudo, embora as empresas, por motivos vários, estejam adotando práticas que ampliam a diversidade, há também "uma quantia considerável de pesquisas indicando que somos atraídos por aqueles que consideramos similares".

$\mathrm{Na}$ atualidade cada vez mais são os estudos que apontam questões voltadas para a diversidade de gênero dentro do ambiente de trabalho.

Nesse sentido, Abu-Saad e Isralowitz (1997, apud Silveira, 2006) que uma pessoa valoriza em relação ao trabalho é poder determinar suas escolhas para a 
carreira, formas de recompensa, resultados em geral, e, se homens e mulheres valorizam diferentes produtos do trabalho, serão diferentes as formas de motivação e satisfação entre eles.

Já Silveira (2016) complementa ao mensurar que "Se homens e mulheres estabelecem diferentes hierarquias de valores em relação ao trabalho, essas distinções podem afetar a satisfação desses trabalhadores e trabalhadoras e, consequentemente, os resultados organizacionais".

A diversidade não apresenta questões voltada a variedade, mais também, a diferenciação em função de fatores externos e internos, vivenciados anteriormente.

\section{MÉTODOS E TÉCNICAS DE PESQUISA}

Esta pesquisa é do tipo bibliográfica, foi consultado obras de autores referenciais no assunto, artigos, revistas, jornais e sites corporativos. Segundo Martins e Theóphilo (2016), a pesquisa bibliográfica é um excelente meio de pesquisa, pois visa a base para a construção da teoria, é necessária para a condução de qualquer pesquisa científica.

A fim de atender o objetivo deste estudo, foi realizado uma pesquisa descritiva conduzida por meio de análise documental e abordagem quantitativa. Uma pesquisa quantitativa é aquela onde os dados e evidências coletadas podem ser quantificados, mensurados. (MARTINS; THEÓPHILO, pg. 107, 2016).

A população do estudo compõe-se do conjunto de companhias abertas da B3, listadas no segmento de Governança Corporativa.

Em um primeiro momento levantamos as empresas listadas na B3, pertencentes aos segmentos de governança Nível 1, Nível 2 e Novo Mercado. Buscou-se informações sobre o perfil da diretoria executiva das companhias diretamente nas páginas de relacionamento com investidores, especificamente a composição entre homens e mulheres. As empresas que não eram transparentes na exposição dos cargos foram excluídas do estudo. Após esses procedimentos adotados, a amostra desta pesquisa foi composta por 175 empresas listadas em diferentes setores econômicos. 
Os dados levantados foram planilhados e organizados de forma que ficasse claro e objetivo para a pesquisa. Realizou-se uma análise geral da distribuição da diretoria entre homens e mulheres, posteriormente uma classificação entre os segmentos de governança e uma análise sobre os setores de atuação.

\section{APRESENTAÇÃO E ANÁLISE DE RESULTADOS}

Esta secção contém a descrição e análise de dados coletados. Apresentamse primeiramente a estatística descritiva dos números e do percentual da distribuição das cadeiras da diretoria executiva das empresas listadas na B3 pertencentes a todos os segmentos de Governança Corporativa. Posteriormente será abordado uma análise setorial.

Inicia-se, pela Tabela 1, expondo-se os dados sobre o número de cadeiras em diretoria executiva das empresas e a distribuição entre homens e mulheres, no ano de 2019.

Tabela 1 - Estatística descritiva da diretoria executiva

\begin{tabular}{l|c|c|c|c|c}
\hline $\begin{array}{l}\text { Segmento } \\
\text { Econômico da } \\
\text { B3 }\end{array}$ & $\begin{array}{c}\text { Integrantes da } \\
\text { Diretoria } \\
\text { Executiva }\end{array}$ & $\begin{array}{c}\text { Total de } \\
\text { Homens }\end{array}$ & $\begin{array}{c}\text { Total de } \\
\text { Homens } \\
(\mathbf{\%})\end{array}$ & $\begin{array}{c}\text { Total de } \\
\text { Mulheres }\end{array}$ & $\begin{array}{c}\text { Total de } \\
\text { Mulheres } \\
(\%)\end{array}$ \\
\hline Nível 1 & 156 & 139 & $89 \%$ & 17 & $11 \%$ \\
\hline Nível 2 & 108 & 100 & $93 \%$ & 8 & $7 \%$ \\
\hline Novo Mercado & 750 & 673 & $90 \%$ & 77 & $10 \%$ \\
\hline Total & $\mathbf{1 . 0 1 4}$ & $\mathbf{9 1 2}$ & $\mathbf{9 0 \%}$ & $\mathbf{1 0 2}$ & $\mathbf{1 0 \%}$ \\
\hline
\end{tabular}

Fonte: B3 (2019). Elaborado pelo autor.

Na tabela 1 é possível observar que as mulheres ocupam apenas $10 \%$ dos assentos disponíveis na diretoria executiva das empresas, somados todos os segmentos de governança. As empresas do segmento Nível 2, apesar de serem maduras no segmento, negociarem ações preferenciais, são as empresas que menos possuem mulheres representando a diretoria executiva, somente $7 \%$. Já as companhias listadas no Nível 1 de Governança Corporativa, ofertam 156 posições em diretoria executiva, distribuídas da seguinte maneira: 139 para executivos e 17 para executivas, um percentual de $11 \%$ para as mulheres. Este foi o segmento que mais apontou mulheres no cargo. As empresas do segmento 
Novo Mercado possuem $10 \%$ dos cargos de direção representado pelo público feminino.

A Tabela 2 apresenta os dados por setor de atuação das empresas listadas no segmento Nível 1 de Governança Corporativa, do ano de 2019. Este segmento é representado por 23 empresas distribuídas em diversos setores.

Tabela 2: Estatística descritiva da diretoria executiva das empresas do segmento Nível 1

\begin{tabular}{|c|c|c|c|c|c|}
\hline Nível 1 & $\begin{array}{c}\text { Integrantes } \\
\text { da Diretoria } \\
\text { Executiva }\end{array}$ & $\begin{array}{l}\text { Total de } \\
\text { Homens }\end{array}$ & $\begin{array}{c}\text { Total de } \\
\text { Homens } \\
(\%)\end{array}$ & $\begin{array}{l}\text { Total de } \\
\text { Mulheres }\end{array}$ & $\begin{array}{c}\text { Total de } \\
\text { Mulheres } \\
(\%)\end{array}$ \\
\hline $\begin{array}{l}\text { Tecidos, Vestuário e } \\
\text { Calçados }\end{array}$ & 12 & 10 & $83 \%$ & 2 & $17 \%$ \\
\hline $\begin{array}{l}\text { Intermediários } \\
\text { Financeiros }\end{array}$ & 54 & 46 & $85 \%$ & 8 & $15 \%$ \\
\hline Mineração & 2 & 2 & $100 \%$ & 0 & $0 \%$ \\
\hline Químicos & 9 & 8 & $89 \%$ & 1 & $11 \%$ \\
\hline Energia Elétrica & 31 & 28 & $90 \%$ & 3 & $10 \%$ \\
\hline Madeira e Papel & 3 & 3 & $100 \%$ & 0 & $0 \%$ \\
\hline Siderurgia e Metalurgia & 21 & 20 & $95 \%$ & 1 & $5 \%$ \\
\hline Material de Transporte & 10 & 10 & $100 \%$ & 0 & $0 \%$ \\
\hline Telecomunicações & 9 & 8 & $89 \%$ & 1 & $11 \%$ \\
\hline Comércio & 5 & 4 & $80 \%$ & 1 & $20 \%$ \\
\hline Total & 156 & 139 & $89 \%$ & 17 & $11 \%$ \\
\hline
\end{tabular}

Fonte: B3 (2019). Elaborado pelo autor.

Observando o resultado coletado do segmento Nível 1 , conclui-se que os setores do Comércio, seguido de Tecidos, Vestuário e Calçados, representados respectivamente pela Cia. Brasileira de Distribuição e Alpargatas, são os que possuem a maior representatividade entre as mulheres executivas, $20 \%$ e $17 \%$. Excluindo os setores que não possuem nenhuma representatividade, os que ficaram com o menor percentual foram Energia Elétrica, seguido de Telecomunicações e Químicos. Analisando isoladamente o setor de Energia Elétrica, a Eletrobrás foi a empresa com o maior número de mulheres na diretoria executiva, 33\%; seguido da COPEL com 14\%. Demais empresas, como: CTEEP, 
CESP, CEMIG e CEEE não possuem mulheres na diretoria executiva. Das 23 empresas listadas neste segmento, 12 empresas não possuem mulheres no seu corpo executivo, um percentual de $53 \%$. Essas empresas somam 56 assentos na diretoria executiva.

Tabela 3: Empresas com maior representatividade de mulheres executivas no Nível 1

\begin{tabular}{l|c|c|c|c|c}
\hline Nível 1 & $\begin{array}{c}\text { Integrantes da } \\
\text { Diretoria } \\
\text { Executiva }\end{array}$ & $\begin{array}{c}\text { Total de } \\
\text { Homens }\end{array}$ & $\begin{array}{c}\text { Total de } \\
\text { Homens } \\
(\mathbf{\%})\end{array}$ & $\begin{array}{c}\text { Total de } \\
\text { Mulheres }\end{array}$ & $\begin{array}{c}\text { Total de } \\
\text { Mulheres } \\
(\%)\end{array}$ \\
\hline $\begin{array}{l}\text { Cia Brasileira de } \\
\text { Distribuição }\end{array}$ & 5 & 4 & $80 \%$ & 1 & $20 \%$ \\
\hline Alpargatas & 12 & 10 & $83 \%$ & 2 & $17 \%$ \\
\hline Total & $\mathbf{1 7}$ & $\mathbf{1 4}$ & $\mathbf{8 2} \%$ & $\mathbf{3}$ & $\mathbf{1 8 \%}$ \\
\hline
\end{tabular}

Fonte: B3 (2019). Elaborado pelo autor.

A Tabela a seguir, apresenta os dados do segmento Nível 2 de Governança Corporativa, este segmento é representado por 19 empresas. Uma das características deste segmento, é que as empresas têm o direito de manter ações preferenciais.

Tabela 4: Estatística descritiva da diretoria executiva das empresas do segmento Nível 2

\begin{tabular}{l|c|c|c|c|c}
\hline Nível 2 & $\begin{array}{c}\text { Integrantes } \\
\text { da Diretoria } \\
\text { Executiva }\end{array}$ & $\begin{array}{c}\text { Total de } \\
\text { Homens }\end{array}$ & $\begin{array}{c}\text { Total de } \\
\text { Homens } \\
\mathbf{( \% )}\end{array}$ & $\begin{array}{c}\text { Total de } \\
\text { Mulheres }\end{array}$ & $\begin{array}{c}\text { Total de } \\
\text { Mulheres } \\
\text { (\%) }\end{array}$ \\
\hline Água e Saneamento & 8 & 7 & $88 \%$ & 1 & $13 \%$ \\
\hline $\begin{array}{l}\text { Intermediários } \\
\text { Financeiros }\end{array}$ & 37 & 36 & $97 \%$ & 1 & $3 \%$ \\
\hline $\begin{array}{l}\text { Petróleo, Gás e } \\
\text { Biocombustível }\end{array}$ & 8 & 6 & $75 \%$ & 2 & $25 \%$ \\
\hline Exploração de Imóveis & 6 & 6 & $100 \%$ & 0 & $0 \%$ \\
\hline Energia Elétrica & 22 & 19 & $86 \%$ & 3 & $14 \%$ \\
\hline Madeira e Papel & 3 & 3 & $100 \%$ & 0 & $0 \%$ \\
\hline $\begin{array}{l}\text { Máquinas e } \\
\text { Equipamentos }\end{array}$ & 4 & 4 & $100 \%$ & 0 & $0 \%$ \\
\hline
\end{tabular}




\begin{tabular}{l|c|c|c|c|c}
\hline Transporte & 8 & 8 & $100 \%$ & 0 & $0 \%$ \\
\hline Previdência e Seguros & 4 & 4 & $100 \%$ & 0 & $0 \%$ \\
\hline Comércio & 8 & 7 & $88 \%$ & 1 & $13 \%$ \\
\hline Total & $\mathbf{1 0 8}$ & $\mathbf{1 0 0}$ & $\mathbf{9 3 \%}$ & $\mathbf{8}$ & $\mathbf{7 \%}$ \\
\hline
\end{tabular}

Fonte: B3 (2019). Elaborado pelo autor.

Examinando o resultado coletado no segmento Nível 2 da B3. Verificou-se que o setor que possui a maior representatividade de mulheres na diretoria executiva é o setor de Petróleo, Gás e Combustível com 25\%, este setor é representado pela Petrobrás, a única empresa deste setor. O segundo setor com maior representatividade é o setor de Energia Elétrica com 14\%, este é representado por seis empresas, a empresa com maior representatividade é a AES Tietê Energia, com 50\% da Diretoria Executiva ocupada por mulheres. Excluindo os setores onde não existe mulheres no cargo de diretora executiva, o setor que menos contribuiu foi o Intermediário Financeiro, com apenas 3\%. Das 19 empresas listadas neste segmento, 12 empresas não possuem mulheres no cargo de diretoras executivas, ou seja, 63\% das empresas listadas.

Tabela 5: Empresas com maior representatividade de mulheres executivas no Nível 2

\begin{tabular}{l|c|c|c|c|c}
\hline Nível 2 & $\begin{array}{c}\text { Integrantes } \\
\text { da Diretoria } \\
\text { Executiva }\end{array}$ & $\begin{array}{c}\text { Total de } \\
\text { Homens }\end{array}$ & $\begin{array}{c}\text { Total de } \\
\text { Homens } \\
\mathbf{( \% )}\end{array}$ & $\begin{array}{c}\text { Total de } \\
\text { Mulheres }\end{array}$ & $\begin{array}{c}\text { Total de } \\
\text { Mulheres } \\
\text { (\%) }\end{array}$ \\
\hline Petrobrás & 8 & 6 & $75 \%$ & 2 & $25 \%$ \\
\hline AES Tietê Energia & 2 & 1 & $50 \%$ & 1 & $50 \%$ \\
\hline Total & $\mathbf{1 0}$ & $\mathbf{7}$ & $\mathbf{7 0 \%}$ & $\mathbf{3}$ & $\mathbf{3 0 \%}$ \\
\hline
\end{tabular}

Fonte: B3 (2019). Elaborado pelo autor.

A empresa AES Tietê Energia foi a empresa que obteve a maior representatividade entre as mulheres no cargo de Diretora Executiva. O setor ainda foi representado pela Energisa e Centrais Elétricas de Santa Catarina, com $20 \%$ e $14 \%$ de mulheres diretoras respectivamente. Alupar, Renova Energia e TAESA, são as empresas que finalizam a composição do setor, não possuem mulheres no cargo de diretoras executivas. 
A Tabela 6, apresenta os dados do segmento Novo Mercado de Governança Corporativa, este segmento é representado por 132 empresas distribuído em 33 setores diferentes. Uma das características deste segmento, é que as empresas podem emitir ações com direito a voto, as chamadas ações ordinárias. Este segmento tornou-se padrão de transparência e governança para novas aberturas de capital, recomendado para empresas que desejam fazer grandes ofertas.

\section{Tabela 6: Estatística descritiva da diretoria executiva das empresas do segmento Novo Mercado}

\begin{tabular}{|c|c|c|c|c|c|}
\hline Novo Mercado & $\begin{array}{c}\text { Integrantes } \\
\text { da Diretoria } \\
\text { Executiva }\end{array}$ & $\begin{array}{l}\text { Total de } \\
\text { Homens }\end{array}$ & $\begin{array}{c}\text { Total de } \\
\text { Homens } \\
(\%)\end{array}$ & $\begin{array}{l}\text { Total de } \\
\text { Mulheres }\end{array}$ & $\begin{array}{c}\text { Total de } \\
\text { Mulheres } \\
(\%)\end{array}$ \\
\hline Agropecuária & 14 & 13 & $93 \%$ & 1 & $7 \%$ \\
\hline Água e Saneamento & 10 & 10 & $100 \%$ & 0 & $0 \%$ \\
\hline Alimentos Processados & 47 & 44 & $94 \%$ & 3 & $6 \%$ \\
\hline $\begin{array}{l}\text { Automóveis e } \\
\text { Motocicletas }\end{array}$ & 5 & 5 & $100 \%$ & 0 & $0 \%$ \\
\hline Comércio & 42 & 37 & $88 \%$ & 5 & $12 \%$ \\
\hline $\begin{array}{l}\text { Computadores e } \\
\text { Equipamentos }\end{array}$ & 4 & 3 & $75 \%$ & 1 & $25 \%$ \\
\hline Construção Civil & 83 & 76 & $92 \%$ & 7 & $8 \%$ \\
\hline $\begin{array}{l}\text { Construção e } \\
\text { Engenharia }\end{array}$ & 9 & 9 & $100 \%$ & 0 & $0 \%$ \\
\hline Diversos & 39 & 36 & $92 \%$ & 3 & $8 \%$ \\
\hline Energia Elétrica & 62 & 50 & $81 \%$ & 12 & $19 \%$ \\
\hline Exploração de Imóveis & 45 & 33 & $73 \%$ & 12 & $27 \%$ \\
\hline Hotéis e Restaurantes & 17 & 12 & $71 \%$ & 5 & $29 \%$ \\
\hline $\begin{array}{l}\text { Intermediários } \\
\text { Financeiros }\end{array}$ & 36 & 32 & $89 \%$ & 4 & $11 \%$ \\
\hline Madeira e Papel & 19 & 17 & $89 \%$ & 2 & $11 \%$ \\
\hline $\begin{array}{l}\text { Máquinas e } \\
\text { Equipamentos }\end{array}$ & 21 & 21 & $100 \%$ & 0 & $0 \%$ \\
\hline Material de Transporte & 16 & 15 & $94 \%$ & 1 & $6 \%$ \\
\hline Mineração & 10 & 9 & $90 \%$ & 1 & $10 \%$ \\
\hline $\begin{array}{l}\text { Petróleo, Gás e } \\
\text { Biocombustível }\end{array}$ & 24 & 23 & $96 \%$ & 1 & $4 \%$ \\
\hline
\end{tabular}


Luís Fernando Gomes Albuquerque, Anderson Sousa Santos

\begin{tabular}{|c|c|c|c|c|c|}
\hline Previdência e Seguros & 20 & 19 & $95 \%$ & 1 & $5 \%$ \\
\hline $\begin{array}{l}\text { Produtos de Uso } \\
\text { Pessoal }\end{array}$ & 5 & 4 & $80 \%$ & 1 & $20 \%$ \\
\hline Programas e Serviços & 18 & 18 & $100 \%$ & 0 & $0 \%$ \\
\hline Químicos & 5 & 5 & $100 \%$ & 0 & $0 \%$ \\
\hline Saúde & 54 & 50 & $93 \%$ & 4 & $7 \%$ \\
\hline Serviços & 8 & 6 & $75 \%$ & 2 & $25 \%$ \\
\hline Serviços Diversos & 2 & 2 & $100 \%$ & 0 & $0 \%$ \\
\hline Serviços Educacionais & 20 & 17 & $85 \%$ & 3 & $15 \%$ \\
\hline Serviços Financeiros & 14 & 13 & $93 \%$ & 1 & $7 \%$ \\
\hline Siderurgia e Metalurgia & 6 & 5 & $83 \%$ & 1 & $17 \%$ \\
\hline $\begin{array}{l}\text { Tecidos, Vestuário e } \\
\text { Calçados }\end{array}$ & 35 & 30 & $86 \%$ & 5 & $14 \%$ \\
\hline Telecomunicações & 6 & 6 & $100 \%$ & 0 & $0 \%$ \\
\hline Transportes & 47 & 46 & $98 \%$ & 1 & $2 \%$ \\
\hline Utilidades Domésticas & 3 & 3 & $100 \%$ & 0 & $0 \%$ \\
\hline Viagens e Lazer & 4 & 4 & $100 \%$ & 0 & $0 \%$ \\
\hline Total & 750 & 673 & $90 \%$ & 77 & $10 \%$ \\
\hline
\end{tabular}

Fonte: B3 (2019). Elaborado pelo autor.

Após os dados coletados no segmento Novo Mercado, levantou-se que o setor que mais possui mulheres no cargo de diretora executiva é o setor de Hotéis e Restaurantes, com $29 \%$ da diretoria executiva composta pelo público feminino. Apontando a empresa International Meal Company, representantes de marcas como: Frango Assado, Viena e Batata Inglesa a maior contribuinte para este setor, com $44 \%$ da sua diretoria representado por diretoras, em seguida a empresa BK Brasil com 13\%. O setor de Exploração de Imóveis com $27 \%$ das suas vagas destinado a mulheres. Este setor é representado por 11 companhias, sendo: Iguatemi S/A e BR Malls Participações S/A as empresas que mais têm mulheres no cargo de diretoras, 50\% para cada entidade. Excluindo os setores que não possuem mulheres na diretoria executiva, o setor de Transporte foi o que menos contribuiu, com apenas $2 \%$ das vagas preenchidas por mulheres. Este setor é representado por 9 companhias, onde apenas uma empresa, a Log-In Logística Future Studies ReseARCh Journal ISSN 2175-5825 SÃo PAUlo, V.11, N.3, P. 346-361, Sep. / Dec. 2019 
Intermodal, possui a diretoria composta por mulheres e homens. O segundo setor com a menor representatividade é o setor de Petróleo, Gás e Biocombustível, este é representado por seis companhias, a única que apresenta mulheres na composição da diretoria executiva é a empresa OSX Brasil. Este segmento é representado por 33 setores, destes, dez não possuem mulheres na composição da diretoria executiva.

Tabela 7: Empresas com maior representatividade de mulheres executivas no Novo Mercado

\begin{tabular}{lc|c|c|c|c}
\hline Novo Mercado & $\begin{array}{c}\text { Integrantes } \\
\text { da Diretoria } \\
\text { Executiva }\end{array}$ & $\begin{array}{c}\text { Total de } \\
\text { Homens }\end{array}$ & $\begin{array}{c}\text { Total de } \\
\text { Homens } \\
\mathbf{( \% )}\end{array}$ & $\begin{array}{c}\text { Total de } \\
\text { Mulheres }\end{array}$ & $\begin{array}{c}\text { Total de } \\
\text { Mulheres } \\
\mathbf{( \% )}\end{array}$ \\
\hline BK Brasil Operações & 8 & 7 & $88 \%$ & 1 & $13 \%$ \\
\hline International Meal S/A & 9 & 5 & $56 \%$ & 4 & $44 \%$ \\
\hline BR Malls Participações S/A & 6 & 3 & $50 \%$ & 3 & $50 \%$ \\
\hline Iguatemi S/A & 6 & 3 & $50 \%$ & 3 & $50 \%$ \\
\hline Total & $\mathbf{2 9}$ & $\mathbf{1 8}$ & $\mathbf{6 2 \%}$ & $\mathbf{1 1}$ & $\mathbf{3 8 \%}$ \\
\hline
\end{tabular}

Fonte: B3 (2019). Elaborado pelo autor.

O setor de Energia Elétrica, nos segmentos de Nível 1 e Nível 2, foi o setor onde obteve empresas com maior representatividade de mulheres na diretoria executiva. No segmento Nível 1 - Centrais Elétricas Brasileiras S/A, com 33\% da diretoria executiva destinado a mulheres e no Nível 2 - AeS Tietê Energia, com $50 \%$; apesar de ser um setor onde o sexo masculino tem maior representatividade, pois a maior parte dos formandos em Engenharia Elétrica são homens. As empresas citadas foram as que obtiveram maior representatividade no Nível 1 e Nível 2. Já no Novo Mercado, as empresas mais representativas foram: BR Malls Participações S/A e Iguatemi S/A.

\section{CONSIDERAÇÕES FINAIS}

O objetivo do estudo foi identificar a disparidade entre homens e mulheres na diretoria executiva das empresas. Para tal, listamos as empresas da B3 pertencentes aos segmentos de Governança Corporativa: Nível 1, Nível 2 e Novo Mercado. O pesquisador escolheu este segmento, por entender que 
empresas que seguem o mais alto padrão de governança, tendem a ser mais harmônicas na igualdade de gêneros, ainda mais que a responsabilidade social é uma prática da governança.

Neste estudo realizou-se uma pesquisa descritiva, conduzida por meio de análise documental e abordagem quantitativa. A amostra foi composta por 175 empresas, sendo 23 empresas listadas no Nível 1, 19 empresas listadas no Nível 2 e 133 listadas no Novo Mercado. Empresas pertencentes a diferentes setores.

Os resultados mostraram que não houve uma disparidade entre os segmentos estudados. O segmento de Nível 1 apresentou entre as empresas listadas 156 posições em diretoria executiva, sendo 139 para executivos e 17 para executivas, um percentual de $89 \%$ para homens e $11 \%$ para as mulheres. 0 segmento de Nível 2 possui 108 vagas na direção executiva distribuída entre as empresas pertencentes a ele. Dessas vagas, 100 posições ou 93\% estão direcionadas aos homens, enquanto 8 vagas ou 7\%, direcionadas as mulheres. Já no segmento com maior número de empresas listadas, o de Novo Mercado, há uma oferta de 750 vagas na direção executiva, sendo 673 para diretores, $90 \%$ e 77 para diretoras, 10\%. Em um olhar geral, são 1.014 posições em direção executiva, destas, 912 cadeiras para homens e 102 cadeiras para mulheres, ou seja, 90 e 10\% respectivamente. Alguns setores, sendo analisados separadamente, tiveram uma contribuição mais favorável às mulheres. No Nível 1 o setor de comércio foi quem mais contribuiu, $20 \%$ das vagas para o público feminino, destaque para a Cia Brasileira de Distribuição. No Nível 2 foi o setor de Petróleo, Gás e Combustível com 25\% das vagas preenchidas por mulheres, destaque para Petrobrás e no segmento Novo Mercado, Hotéis e Restaurantes com 29\%, destaque para BR Malls e Iguatemi S/A.

Respondendo à questão desta pesquisa: O fato de as empresas estarem listadas num segmento voltado à adoção de práticas de Governança Corporativa, faz com que elas adotem a mesma proporcionalidade na diretoria executiva entre homens e mulheres? Não. Ficou evidente que existe uma desproporção acentuada entre executivos homens e mulheres na diretoria dessas companhias.

As mulheres na sociedade moderna não aceitam mais os padrões de antes. Elas saem para trabalhar, estudar, construir sua carreira, socializar-se. As transformações na sociedade e na concepção de família, são cada vez mais constantes. Hoje temos muitos exemplos de homens se dedicando a casa e aos 
filhos e as mulheres saindo para o trabalho, isso fez com que a sociedade feminina mudasse sua forma de se relacionar com as empresas. Porém, o estudo constatou que as empresas listadas em tais segmentos, apesar de terem elevados padrões de governança corporativa, possuem os cargos de alta gestão dominados por homens. O debate pela diversidade de gênero nas empresas não é passageiro. Segundo Luís Sérgio Vieira, presidente da Ernest Young (2017), ter mulheres na liderança é uma estratégia racional para os negócios. É preciso criar um incentivo dentro das organizações, para que as mulheres possam aumentar sua ocupação dentro das diretorias executivas. O aumento da proximidade masculina à questão da diversidade de gênero, promover adaptações, identificar pontos onde possam perder mulheres com potencial de liderança, são algumas medidas que as companhias podem adotar.

\section{REFERÊNCIAS}

B3 - BRASIL, BOLSA, BALCÃO. Segmento de listagem. Disponível em: $<$ http://www.b3.com.br/pt br/produtos-e-servicos/negociacao/rendavariavel/empresas-listadas.htm> Acesso em: 02/07/2019.

CARVAlHO, A. G. (2002) Governança Corporativa no Brasil em perspectiva. Revista de Administração. v. 37, n. 3, p. 19-32.

COX, T. H.; BLAKE, S. (1991) Managing Cultural Diversity: Implications for organisational competitiveness. Academy of Management Executive. v. 5, n. 3.

DADFAR, H.; GUSTAVSSON, P. (1992) Competition by Effective Management of Cultural Diversity: The case of International Constructions Project. International Studies of Management \& Organization, v. 22, n. 4.

DONALDSON, L.; DAVIS, H. J. (1991) Stewardship Theory or Agency Theory: CEO Governance and Shareholder Returns. Australian Journal of Management.

IBGC - INSTITUTO BRASILEIRO DE GOVERNANÇA CORPORATIVA. (2015) Código das melhores práticas de governança corporativa. 5a ed. São Paulo.

LEWGOY, Júlia. Por que diversidade de gênero nas empresas significa mais lucro? EXAME. 19/10/2017. Disponível em: <https://exame.abril.com.br/carreira/por-que-diversidade-de-genero-nasempresas-significa-mais-lucro/ > Acesso em: 09/07/2019.

MACHADO JUNIOR, C.; PALMISANO, A.; MAZZALI, L. CAMPANÁRIO, M. A. (2015) O conhecimento em Governança Corporativa. Santa Catarina, v. 12, n. 26, p. 99-118. 
MARTINS, G. de A.; THEÓPHILO, C. R. (2016) Metodologia da Investigação Científica: para Ciências Sociais Aplicadas. 3a. ed. São Paulo: Atlas.

MAYER, C. (2012) Firm Commitment. Oxford University Press.

MINTZBERG, H. (2003) Criando Organizações Eficazes. 2a. ed. São Paulo: Atlas.

MOREIRA, Assis. Mulher no comando de empresas dá mais lucro também no Brasil, diz OIT. Valor Econômico. 22/05/2019. Disponível em: <https://valor.globo.com/carreira/recursos-humanos/coluna/mulher-nocomando-de-empresas-da-mais-lucro-tambem-no-brasil-diz-oit.ghtml> Acesso em: 16/07/2019.

NUNES, Ana Carolina. Igualdade de gênero nas empresas deve ser estabelecida por cotas e metas, defendem CEOs. Época Negócios. 27/06/2018. Disponível em: <https://epocanegocios.globo.com/Carreira/noticia/2018/06/igualdadede-genero-nas-empresas-deve-ser-estabelecida-por-cotas-e-metasdefendem-ceos.html>. Acesso em: 14/07/2019

ROSSETTI, J. P.; ANDRADE, A. (2016) Governança Corporativa: fundamentos, desenvolvimento e tendências. 7a. ed. São Paulo: Atlas.

SILVEIRA, A. D. M. da. (2015) Governança Corporativa: no Brasil e no Mundo. $2 a$. ed. Rio de Janeiro: Elsiever.

SILVEIRA, N. S. P da. (2006) A Diversidade de Gênero e as Diferenças e Semelhanças na hierarquia de valores do trabalho de homens e mulheres no chão de fábrica. São Paulo, v. 13, n. especial, p. 77-91.

TIROLE, J. (2001) Corporate Governance. Econometrica, v.69, n. 1, pp. 1-35.

VALENTE, P. G. (2018) Governança Corporativa: guia do conselheiro para empresas familiares ou fechadas. Rio de Janeiro: Alta Books. 